Acta Crystallographica Section B

Structural

Science

ISSN 0108-7681

\section{Nouzha Bouhmaida, ${ }^{\mathrm{a}}$ François Bonhomme, ${ }^{\mathrm{b}}$ Benoît Guillot, ${ }^{\mathrm{c}}$ Christian Jelsch ${ }^{\mathrm{c}}$ and Nour Eddine Ghermani ${ }^{\mathrm{b}, \mathrm{d}}$ *}

aLSM, Laboratoire des Sciences des Matériaux, Université Cadi Ayyad, Faculté des Sciences Semlalia, Boulevard Prince Moulay Abdallah, BP 2390, 40000 Marrakech, Morocco, 'bPB, Laboratoire Physico-Chimie-PharmacotechnieBiopharmacie, UMR CNRS 8612, Université Paris-Sud 11, Faculté de Pharmacie, 5 rue JeanBaptiste Clément, 92296 Châtenay-Malabry, France, ${ }^{\mathrm{C}} \mathrm{LCM} 3 \mathrm{~B}$, Laboratoire de Cristallographie et Modélization des Matériaux Minéraux et Biologiques, UMR CNRS 7036, Nancy Université, Faculté des Sciences et Techniques, BP 239, 54506 Vandoeuvre-lès-Nancy, France, and d SPMS, Laboratoire Structures et Propriétés des Matériaux Solides, UMR CNRS 8580, Ecole Centrale Paris, Grande Voie des Vignes, 92290 Châtenay-Malabry, France

Correspondence e-mail: noureddine.ghermani@u-psud.fr

\title{
Charge density and electrostatic potential analyses in paracetamol
}

The electron density of monoclinic paracetamol was derived from high-resolution X-ray diffraction at $100 \mathrm{~K}$. The HansenCoppens multipole model was used to refine the experimental electron density. The topologies of the electron density and the electrostatic potential were carefully analyzed. Numerical and analytical procedures were used to derive the charges integrated over the atomic basins. The highest charge magnitude $(-1.2 \mathrm{e})$ was found for the $\mathrm{N}$ atom of the paracetamol molecule, which is in agreement with the observed nucleophilic attack occurring in the biological media. The electric field generated by the paracetamol molecule was used to calculate the atomic charges using the divergence theorem. This was simultaneously applied to estimate the total electrostatic force exerted on each atom of the molecule by using the Maxwell stress tensor. The interaction electrostatic energy of dimers of paracetamol in the crystal lattice was also estimated.

\section{Introduction}

Ultra-high-resolution X-ray diffraction experiments are very accurate nowadays and enable us to extract the precise electron-density distribution in crystalline materials. From the electron density it is possible to derive one-electron properties such as the electrostatic potential and other atomic or molecular moments. For many years we have been involved in the developments of electrostatic property methodologies and calculations. In our recent research, a software to calculate the forces acting on atoms in the molecules has been developed (Bouhmaida \& Ghermani, 2008). We have previously characterized the electrostatic potential through its first derivative, i.e. the electric field and its critical points (Bouhmaida et al., 2002). All these calculations are based on the HansenCoppens multipolar atom model (Hansen \& Coppens, 1978) which is widely used in the refinement of high-resolution diffraction data. Our applications are mainly dedicated to pharmaceutical and biologically active molecules. It is important to provide accurate electrostatic parameters for drugs to understand their mode of action. Such parameters can also be used in further investigations like modelling and docking drugs into binding sites of enzymes and proteins, where the choice of force fields is a crucial problem. Paracetamol (acetaminophen) is a widely used analgesic and antipyretic drug throughout the world. It presents a weak antiinflammatory action and has moderate side effects compared with aspirin. The mode of action of paracetamol in the nervous system has been very recently described by Högestätt et al. (2005). It was shown that the main metabolite of paracetamol is the $p$-aminophenol (after deacetylation) which interacts
Received 23 October 2008 Accepted 6 March 2009
(C) 2009 International Union of Crystallography Printed in Singapore - all rights reserved 
Table 1

Experimental and refinement details for paracetamol.

\begin{tabular}{|c|c|c|}
\hline \multicolumn{3}{|l|}{ Crystal data } \\
\hline Chemical formula & $\mathrm{C}_{8} \mathrm{H}_{9} \mathrm{NO}_{2}$ & \\
\hline$M_{r}$ & 151.16 & \\
\hline Crystal system, space group & Monoclinic, $P 2_{1} / n$ & \\
\hline Temperature (K) & $100(1)$ & \\
\hline$a, b, c(\AA)$ & $7.0915(3), 9.2149(4), 11.6015(5)$ & \\
\hline$\beta\left({ }^{\circ}\right)$ & $97.8650(10)$ & \\
\hline$V\left(\AA^{3}\right)$ & $751.00(6)$ & \\
\hline$Z$ & 4 & \\
\hline Radiation type & Mo $K \alpha$ & \\
\hline Wavelength $(\AA)$ & 0.71069 & \\
\hline$\mu\left(\mathrm{mm}^{-1}\right)$ & 0.097 & \\
\hline Crystal form, size (mm) & Block, $0.42 \times 0.35 \times 0.28$ & \\
\hline \multicolumn{3}{|l|}{ Data collection } \\
\hline Diffractometer & SMART 1000 CCD & \\
\hline Data-collection method & $\mathrm{CCD}$ & \\
\hline Absorption correction & Empirical & \\
\hline $\begin{array}{l}\text { No. of measured, independent } \\
\text { and observed reflections }\end{array}$ & $45383,9441,6435$ & \\
\hline Criterion for observed reflections & $I>3 \sigma(I)$ & \\
\hline$(\sin \theta / \lambda)_{\max }\left(\AA^{-1}\right)$ & 1.212 & \\
\hline$R_{\text {int }}$ & 0.025 & \\
\hline$\theta_{\max }\left({ }^{\circ}\right)$ & 59.5 & \\
\hline Spherical refinement method & Full-matrix least-squares on $F^{2}$ & \\
\hline Data/restraints/parameters & $9441 / 0 / 137$ & \\
\hline Goodness-of-fit on $F^{2}$ & 1.032 & \\
\hline Final $R$ indices $[I>2 \sigma(I)]$ & $R_{1}=0.0345, w R_{2}=0.1023$ & \\
\hline$R$ indices (all data) & $R_{1}=0.0465, w R_{2}=0.1106$ & \\
\hline $\begin{array}{l}\text { Largest difference peak and hole } \\
\quad\left(\mathrm{e} \AA^{-3}\right)\end{array}$ & 0.539 and -0.276 & \\
\hline Multipolar refinement method & Full-matrix least-squares on $F$ & \\
\hline Data/restraints/parameters & $6435 / 0 / 278$ & $4737 / 0 / 278 \dagger$ \\
\hline Goodness-of-fit on $F$ & 0.887 & $0.790 \dagger$ \\
\hline Final $R$ indices $[I>3 \sigma(I)]$ & $R_{F}=0.0180 w R_{F}=0.0205$ & $R_{F}=0.0144 w R_{F}=0.0164 \dagger$ \\
\hline & $R_{F^{2}}=0.0216, w R_{F^{2}}=0.0401$ & $R_{F^{2}}=0.0197, w R_{F^{2}}=0.0323 \dagger$ \\
\hline
\end{tabular}

$\dagger$ Obtained indices for cut-off data at $\sin \theta / \lambda=1.02 \AA^{-1}$ corresponding to a data completeness of $100 \%$.

obtained to a resolution of $1.02 \AA^{-1}$. The contribution of the remaining high-order and incomplete data (one third of the measured unique reflections) to the results is discussed and illustrated by the electrondensity maps. The topologies of the electron density and the electrostatic potential were carefully analyzed. The atomic charges and the electrostatic forces acting on the atoms in paracetamol molecule are presented and discussed. The interaction electrostatic energy between molecules in the crystal is also estimated.

\section{Experimental}

Crystals of paracetamol were grown by slow evaporation from a saturated aqueous solution. Only the stable monoclinic phase of paracetamol was obtained in this case. A suitable colourless blocklike crystal sample was chosen for the high-resolution X-ray diffraction experiment which was carried out at $100 \mathrm{~K}$ on a Siemens Smart CCD 1K diffractometer using Mo $K \alpha$ radiation (graphite monochromator). The cell parameters obtained are in very good agreement with those reported at $123 \mathrm{~K}$ (Nichols \& Frampton, 1998). The data were collected for five different positions of the CCD detector, ranging from -25 to $+75^{\circ}$ in the $2 \theta$ position (9300 frames). The exposure time for each frame varied between 15 and $60 \mathrm{~s}$ from low to high Bragg angles. A standard

with arachidonic acid to form the AM404 inhibitor.

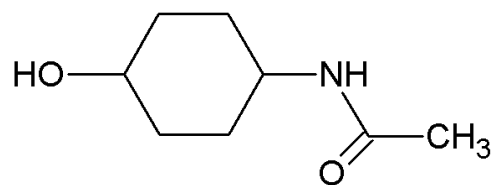

In the solid state, paracetamol exhibits two phases, the monoclinic form I (Haisa et al., 1976) and the orthorhombic form II (Nichols \& Frampton, 1998). Solvates and hydrates of paracetamol have also been reported in the literature (Di Martino et al., 1997; McGregor et al., 2002; Parkin et al., 2002). The monoclinic form of paracetamol is the most stable polymorph and is easy to obtain in a standard crystallization process. The orthorhombic form is, however, the most relevant form pharmaceutically for compression into tablets (Jain, 1999). In the present study the experimental electron density distribution in monoclinic paracetamol has been derived from $\mathrm{X}$-ray diffraction data collected at $100 \mathrm{~K}$ to a resolution of $\sin \theta / \lambda=1.21 \AA^{-1}$. Completeness $(100 \%)$ of the data was only scan width of $0.3^{\circ}$ in $\omega$ was chosen for this experiment in order to reconstruct the intensity peak profiles. A total of 45383 reflections were collected up to a resolution of $\sin \theta / \lambda=$ $1.21 \AA^{-1}$ (in direct space, $d=0.41 \AA$ ). The Bragg intensities were integrated with the SMART software packages (Bruker, $1998 a, b, c)$. Sorting, merging and application of the empirical absorption correction for the dataset were performed using SORTAV (Blessing, 1995). Table 1 gives the experimental and refinement details. ${ }^{1}$ Table 2 gives the completeness of the data with respect to the resolution as obtained after the data reduction. Completeness was reached for data with $\sin \theta / \lambda<$ $1.02 \AA^{-1}$ (4737 unique reflections versus 6435 data in the full dataset). Less complete data at a high angle are generally obtained for organic material due to the thermal smearing. High-order data are, however, necessary for a better deconvolution of the thermal motion and the electron-density parameters during the refinements. As shown in Table 1, the statistical indices are improved for data cut off at $1.02 \AA^{-1}$.

\footnotetext{
${ }^{1}$ Supplementary data for this paper are available from the IUCr electronic archives (Reference: GW5002). Services for accessing these data are described at the back of the journal.
} 
Table 2

Distribution of measured and missing reflections in equal-volume resolution shells.

\begin{tabular}{lllll}
\hline$(\sin \theta / \lambda)_{\max }$ & $d_{\min }$ & Measured & Missing & Completeness $(\%)$ \\
\hline 0.4467 & 1.119 & 562 & 1 & 99.8 \\
0.5628 & 0.888 & 555 & 0 & 100.0 \\
0.6442 & 0.776 & 557 & 0 & 100.0 \\
0.7091 & 0.705 & 565 & 0 & 100.0 \\
0.7638 & 0.655 & 561 & 1 & 99.8 \\
0.8117 & 0.616 & 560 & 5 & 99.1 \\
0.8545 & 0.585 & 544 & 5 & 99.1 \\
0.8934 & 0.560 & 563 & 13 & 97.7 \\
0.9292 & 0.538 & 545 & 17 & 97.0 \\
0.9624 & 0.520 & 542 & 24 & 95.8 \\
0.9934 & 0.503 & 521 & 26 & 95.2 \\
1.0227 & 0.489 & 510 & 59 & 89.6 \\
1.0503 & 0.476 & 497 & 62 & 88.9 \\
1.0766 & 0.464 & 469 & 70 & 87.0 \\
1.1016 & 0.454 & 515 & 79 & 86.7 \\
1.1256 & 0.444 & 313 & 235 & 57.1 \\
1.1486 & 0.435 & 304 & 252 & 54.7 \\
1.1707 & 0.427 & 303 & 272 & 52.7 \\
1.1920 & 0.419 & 271 & 275 & 49.6 \\
1.2125 & 0.412 & 184 & 370 & 33.2 \\
& & &
\end{tabular}

Other effects of completeness on the refined properties will be discussed below. In our study, the structure of paracetamol was solved by direct methods using SHELXS97 (Sheldrick, 2008) in space group $P 2_{1} / n$ (Nichols \& Frampton, 1998) and refined in the spherical-atom approximation (based on $F^{2}$ ) using SHELXL97 (Sheldrick, 2008) as included in the WinGX package of programs (Farrugia, 1999). The crystal structure of paracetamol was first reported in the space group $P 2_{1} / a$ (Haisa et al., 1976). This also holds true for the recent study reporting the variation of cell parameters of paracetamol from 30 to $330 \mathrm{~K}$ using neutron diffraction (Wilson, 2000). The molecular displacement ellipsoid plots were generated using ORTEPIII (Burnett \& Johnson, 1996). Fig. 1 shows the ORTEP view of the molecule and the numbering scheme used in this study.

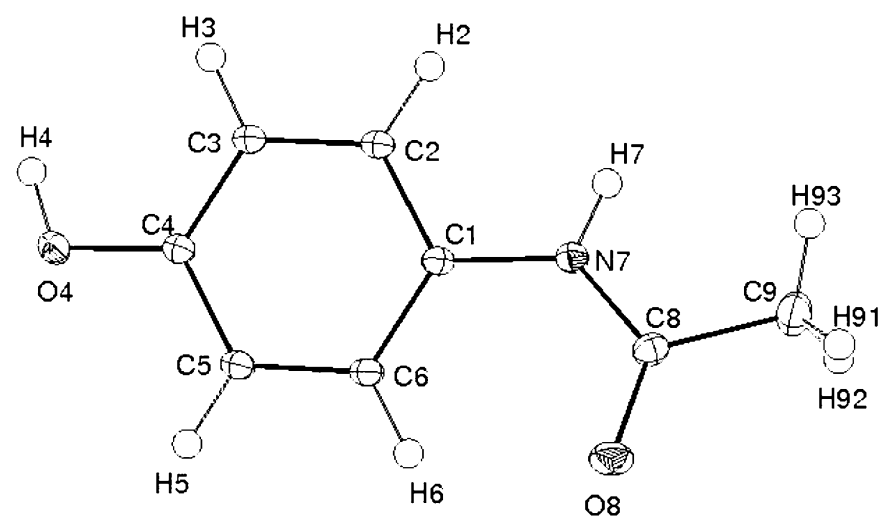

Figure 1

ORTEP representation of the molecular structure of paracetamol and the atom-numbering scheme. Displacement ellipsoids are drawn at the $50 \%$ probability level.

\section{Methods}

\subsection{Electron-density refinements}

The experimental electron density was obtained by refinement of the collected X-ray data. In the present study, we used the least-squares MOLLY program (Hansen \& Coppens, 1978) in which each pseudo-atom in the molecule has a corresponding electron density

$$
\begin{aligned}
\rho_{\text {model }}(\underline{r})= & \rho_{\text {core }}(r)+P_{\mathrm{val}} \kappa^{3} \rho_{\text {val }}(\kappa r) \\
& +\kappa^{\prime} \sum_{l=0}^{l_{\max }} R_{n l}\left(\kappa^{\prime} r\right) \sum_{m=0}^{l} P_{l m \pm} y_{l m \pm}(\theta, \varphi),
\end{aligned}
$$

where $\rho_{\text {core }}$ and $\rho_{\text {val }}$ are spherically symmetric Hartree-Fock core and valence electron densities (Clementi \& Roetti, 1974). In this model, $R_{n l}(r)$ is a radial function of the Slater type. In the fit procedure to experimental data, the refined $P_{\text {val }}$ and $P_{l m \pm}$ parameters correspond to the valence and multipole populations. The $\kappa$ and $\kappa^{\prime}$ coefficients take into account the contraction-expansion of the valence electron density (Coppens et al., 1979). During the refinements, the octupolar level $(l=3)$ of the multipole expansion was used for $\mathrm{C}, \mathrm{O}$ and $\mathrm{N}$ atoms, whereas for $\mathrm{H}$ atoms, the dipolar level $(l=1)$ was applied. Fig. 2 depicts the final residual electron density as obtained after the multipolar refinement showing the good agreement between the observed and calculated electron densities. These maps were calculated with all reflections for $\sin \theta / \lambda<1.02 \AA^{-1}$ and $<1.21 \AA^{-1}$. The average internal (Cruickshank, 1949) and external (Rees, 1976) experimental

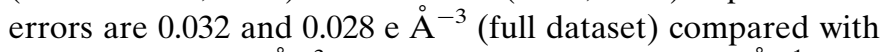

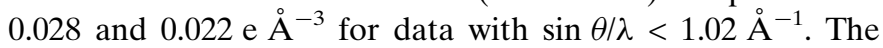
highest residue $\left(0.15 \mathrm{e} \AA^{-3}\right.$ for full data and $0.10 \mathrm{e} \AA^{-3}$ for cut-off data at $\sin \theta / \lambda=1.02 \AA^{-1}$ ) is found in the $\mathrm{C} 4-\mathrm{O} 4$ bond. All other residues are out of the atomic bonds and are not significant. The high-order data (1698 additional unique reflections) did not decrease the quality of the refinements and add randomly on average one contour in the residual maps $\left(0.05\right.$ e $\left.\AA^{-3}\right)$.

\subsection{Electrostatic potential, field and interaction energy}

The electrostatic potential $\Phi(\underline{r})$ at any point $\underline{r}$ around the molecule is calculated as

$$
\Phi(\underline{r})=\sum_{j}^{N} \frac{Z_{j}}{\left|\underline{r}-\underline{R}_{j}\right|}-\int \frac{\rho_{\text {model }, j}\left(\underline{r}^{\prime}\right)}{\left|\underline{r}-\underline{R}_{j}-\underline{r}^{\prime}\right|} \mathrm{d} \underline{r}^{\prime},
$$

where each atom $j$ is at position $R_{j}$ in the crystal lattice, $Z_{j}$ being its nuclear positive charge (Ghermani et al., 1992a,b,c; Bouhmaida et al., 1997). In (2) $N$ is the total number of atoms in the chemical system or molecule under consideration. The electric field is the negative gradient of the electrostatic potential $\underline{E}(\underline{r})=-\underline{\nabla} \Phi(\underline{r})$. Both the electrostatic potential and field exhibit the nucleophilic and electrophilic regions of the molecule and thus are related to the molecular reactivity. The electric field components were analytically calculated by our computer program FIELD based on the Hansen-Coppens electron-density model described above (Ghermani et al., 
1992c; Bouhmaida et al., 2002). The flux of the gradient lines of the electrostatic potential $\underline{\nabla} \Phi(\underline{r})$ vanishes through atomic basin surfaces, where the atomic charge is zero (Bouhmaida et $a l ., 2002)$. In an interatomic bond, the zero of the gradient of the electrostatic potential $\underline{\nabla} \Phi(\underline{r})$ defines a critical point $(\mathrm{CP})$. The distance from each atom of the bond to the critical point yields the atomic covalent radii (Bouhmaida et al., 2002; Novaković et al., 2007). Finally, the electrostatic interaction energy between molecules was estimated by the method
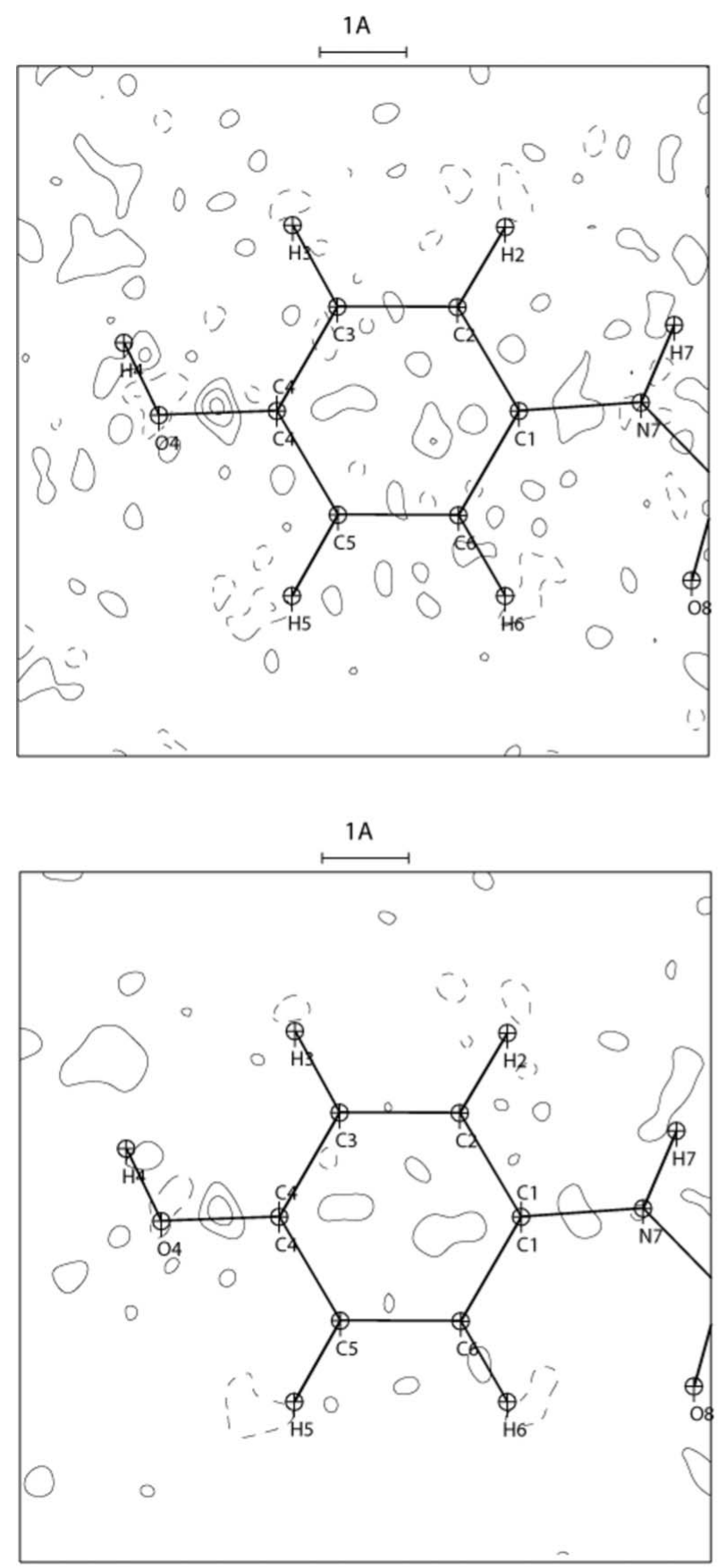

(a)

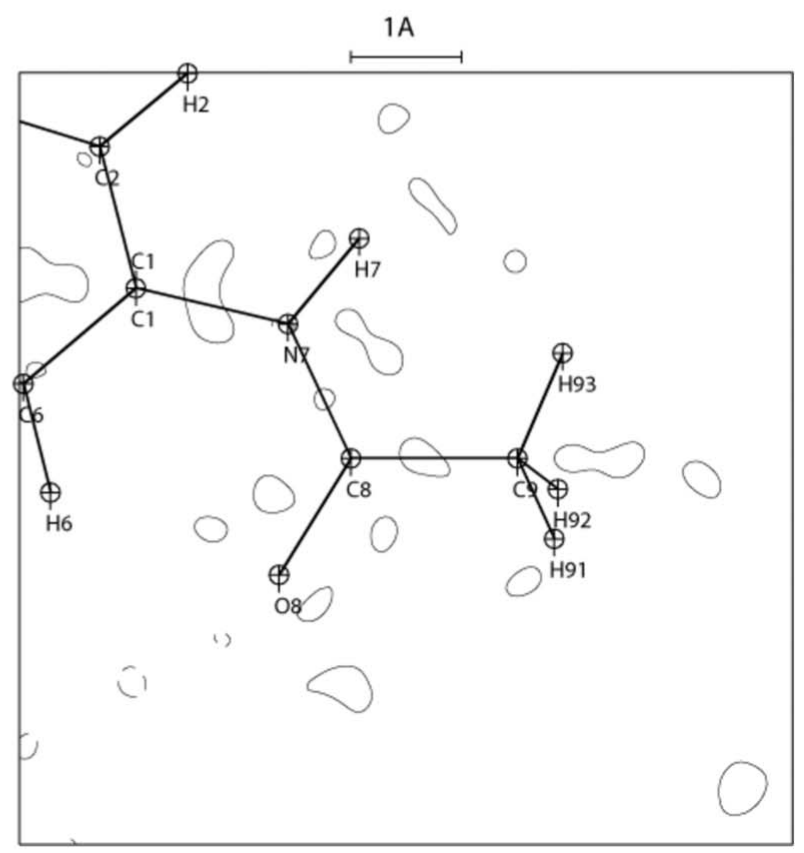

developed in MOPRO and VMOPRO computer programs (Guillot et al., 2001; Jelsch et al., 2005).

\subsection{Topological analyses and derived atomic charges}

The topological analysis of the electron density $\rho(\underline{r})$ was carried out using the NEWPROP program (Souhassou, 1999; Souhassou \& Blessing, 1999). Based on the AIM (Atoms in Molecules) theory (Bader, 1990), this analysis allows a quan-

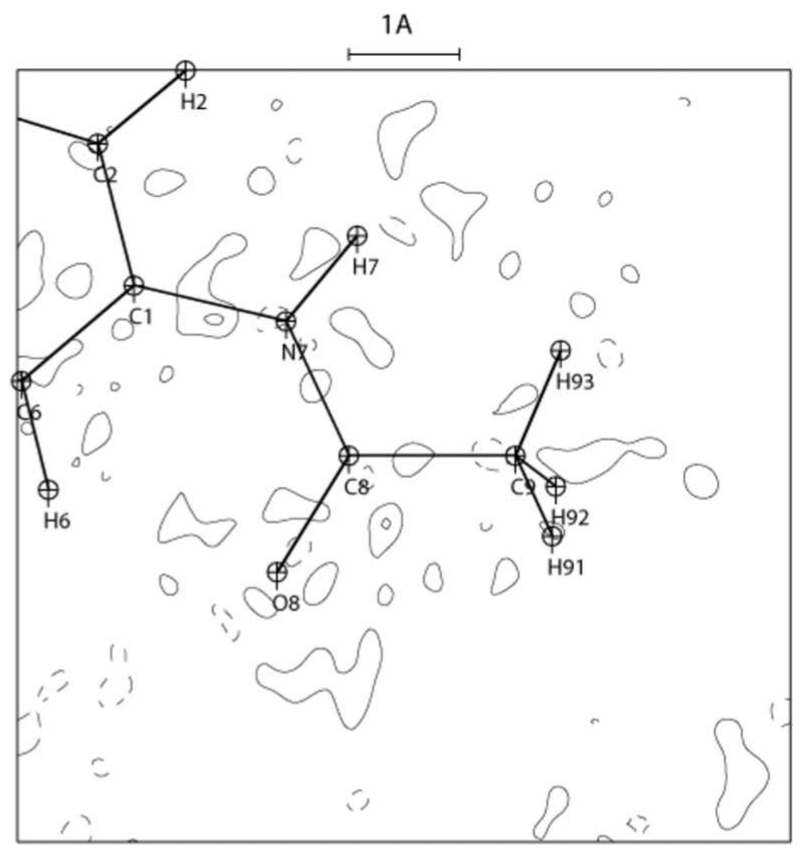

(b)

Figure 2

Residual electron density in the two main planes of paracetamol molecules: (a) full dataset; $(b)$ cut-off data at $\sin \theta / \lambda=1.02 \AA^{-1}$. Contour intervals are 0.05 e $\AA^{-3}$; solid lines represent positive contours, dashed lines are negative contours and the zero contour is omitted. 
titative description of the covalent or ionic bonds, nonbonding interactions and electronic structure of atoms in molecules. The gradient of the electron density $\underline{\nabla} \rho\left(\underline{r}_{\mathrm{CP}}\right)$ vanishes at the critical points (CP) corresponding to the extrema and saddle points of $\rho(\underline{r})$. The Hessian matrix [tensor of second partial derivatives of $\rho(\underline{r})]$ generated at CP points is then diagonalized yielding three eigenvalues $\lambda_{1}, \lambda_{2}$ and $\lambda_{3}$. Their corresponding sum is the Laplacian of the electron density $\nabla^{2} \rho\left(r_{\mathrm{CP}}\right)$. Each critical point $(\mathrm{CP})$ is therefore characterized by two numbers: the number of different eigenvalues (for non-degenerate cases) and the sum of the signs of the three eigenvalues. Therefore, $(3,-1)$ CP's correspond to common covalent bonds and $(3,+1)$ CP's to ring critical points. The ellipticity $\varepsilon=\left(\lambda_{1}-\lambda_{2}\right) / \lambda_{2}$ is an important index of the type of the chemical bonds ( $\sigma$ or $\pi$ ) and was recently used to characterize electrocyclic reactions (Silva López et al., 2005). On the other hand, the atomic basins delimited by the zeroflux surfaces of the gradient of the electron density are used to integrate physical properties like AIM atomic charges or moments.

The method used in the NEWPROP program is based on analytical calculations of topological properties and atomic surfaces. Recently, an entirely numerical and robust computation to define the atomic basins and to integrate the electrons to obtain AIM charges was developed by Henkelman et al. (2006) and is based on the steepest ascent algorithm (Sanville et al., 2007). This approach has been implemented in the BADERWIN program (Sanville et al., 2007). We have recently shown that the integrated atomic charges obtained by this numerical procedure are as accurate as those using sophisticated methods for experimental electron density (Courcot et al., 2007). Moreover, the BADERWIN program provides the volume of each atom in a separate file which is very useful for further integration or to define the atomic surface. From the Gauss divergence theorem, AIM charges $Q$ can also be estimated by the flux of the electric field $\underline{E}$ (Popelier, 2001; Bouhmaida \& Ghermani, 2008) generated by the total charge distribution, including the positive charge of the nucleus, through the atomic basin surface $S$ having vectors $\underline{n}$ as normals

$$
\nabla \cdot \underline{E}=\rho_{\mathrm{t}} \Rightarrow \oint_{S} \underline{E} \cdot \underline{n} \mathrm{~d} S=Q
$$

Here $\rho_{\mathrm{t}}$ is the total charge density including the nuclear charge. Thanks to the GHS3D program (George, 1996) this atomic surface can be triangulated, using a rigorous Delaunay triangulation method, in order to numerically calculate the flux of the electric field as defined in (3).

\subsection{Electrostatic forces}

The Maxwell stress tensor $\sigma_{\mathrm{M}}$ can be expressed from the three components of the electric field $E_{x}, E_{y}$ and $E_{z}$ at each point $\underline{r}$ with respect to an orthonormal basis by

$$
\begin{aligned}
\sigma_{\mathrm{M}}(\underline{r}) & =\left(\begin{array}{ccc}
E_{x}^{2} & E_{x} E_{y} & E_{x} E_{z} \\
E_{x} E_{y} & E_{y}^{2} & E_{y} E_{z} \\
E_{x} E_{z} & E_{y} E_{z} & E_{z}^{2}
\end{array}\right)-\frac{E^{2}}{2}\left(\begin{array}{ccc}
1 & 0 & 0 \\
0 & 1 & 0 \\
0 & 0 & 1
\end{array}\right) \\
& =\underline{E}(\underline{r}) \otimes \underline{E}(\underline{r})-\frac{E^{2}(\underline{r})}{2} \delta^{(2)},
\end{aligned}
$$

where $\delta^{(2)}$ is the identity tensor of the order 2. For simplicity, $\sigma_{\mathrm{M}}$ is multiplied by $4 \pi$. The divergence of the Maxwell tensor gives

$$
\nabla \cdot \sigma_{\mathrm{M}}=\nabla \cdot \underline{E} \underline{E}-\underline{E} \times(\nabla \times \underline{E})
$$

In the absence of a magnetic field (or when the magnetic field is independent of time), the rotational of $E$ vanishes and then

$$
\nabla \cdot \sigma_{\mathrm{M}}=\nabla \cdot \underline{E} \underline{E}=\rho_{t}(\underline{r} \underline{E} \underline{(r}) .
$$

The total electrostatic force acting on atom $A$ with a basin volume $\Omega$ can then be expressed as

$$
\underline{F}(A)=\int_{\Omega} \nabla \cdot \sigma_{\mathrm{M}}(\underline{r}) \mathrm{d} \underline{r}=\int_{\Omega} \nabla \cdot \underline{E}(\underline{r}) \underline{E}(\underline{r}) \mathrm{d} \underline{r}=\int_{\Omega} \rho_{t}(\underline{r}) \underline{E}(\underline{r}) \mathrm{d} \underline{r} .
$$

Here again the total charge density is $\rho_{\mathrm{t}}(\underline{r})=\rho_{\mathrm{n}}(\underline{r})-\rho(\underline{r})=$ $\mathrm{Z} \delta(\underline{r}-\underline{R})-\rho(\underline{r})$ where $\rho_{\mathrm{n}}$ and $\rho$ are the nuclear and electronic charge distributions. Therefore, the total electrostatic force can be expressed as

$$
\underline{F}(A)=Z \underline{E}(\underline{R})-\int_{\Omega} \rho(\underline{r}) \underline{E}(\underline{r}) \mathrm{d} \underline{r} .
$$

The sum of the Feynman force acting on the nucleus [here $E(\underline{R})$ is the electric field at the nucleus] and the second term which is the force acting on the electrons within the basin of the atom, that is, the Ehrenfest force (Bader, 1998; Bader et al., 2007; Hernández-Trujillo et al., 2007; Bouhmaida \& Ghermani, 2008). For molecules at equilibrium, the Feynman force on each nucleus is zero. However, that is not the case when experimental electron density is used (Bouhmaida \& Ghermani, 2008, and references therein). In our calculations we use the divergence theorem to estimate the total electrostatic forces acting on atoms of the molecule

$$
\underline{F}(A)=\int_{\Omega} \nabla \cdot \sigma_{\mathrm{M}}(\underline{r}) \mathrm{d} \underline{r}=\int_{S} \sigma_{\mathrm{M}}(\underline{r}) \underline{n} \mathrm{~d} S .
$$

Likewise for the charges, the atomic surface is triangulated and the flux is calculated numerically. This method is more reliable because it avoids the problem of the volume integration [see (7)], especially for points close to the nucleus. In this paper we will focus on the calculation of the modulus of the total electrostatic force [see (9)] acting on each atomic basin.

\section{Results and discussion}

\subsection{Effect of the data completeness on the refinements}

Beyond the resolution of $\sin \theta / \lambda=1.02 \AA^{-1}$, the collected data were not complete (Table 2). As is known in charge- 
density studies, high-order data bring important information for the determination of atomic positions and thermal parameters. They permit a better deconvolution of the structural parameters on one hand and the density parameters on the other. In this study 1698 high-order data were collected. We have shown in the previous sections that the statistical indices (Table 1) are improved and the residual maps are very slightly clearer. In order to highlight the contribution of the highorder data, we have compared the experimental deformation density maps \{Fourier transform of the difference $\left[F_{\text {obs }}(\right.$ mulobs(multipole phase $)-F_{\text {calc }}$ (spherical model)] where $F_{\text {obs }}$ and $F_{\text {calc }}$ are the observed and calculated structure factors $\}$ and the static deformation density maps. All these maps are depicted in Fig. 3. The main features appear in the vicinity of the $\mathrm{O} 8$ atom lone pairs. For the full data, the electron density in the lone-pair region is well resolved in comparison to that corresponding to the cut-off data. That is clearly shown in both experimental and static electron-density maps. The confidence
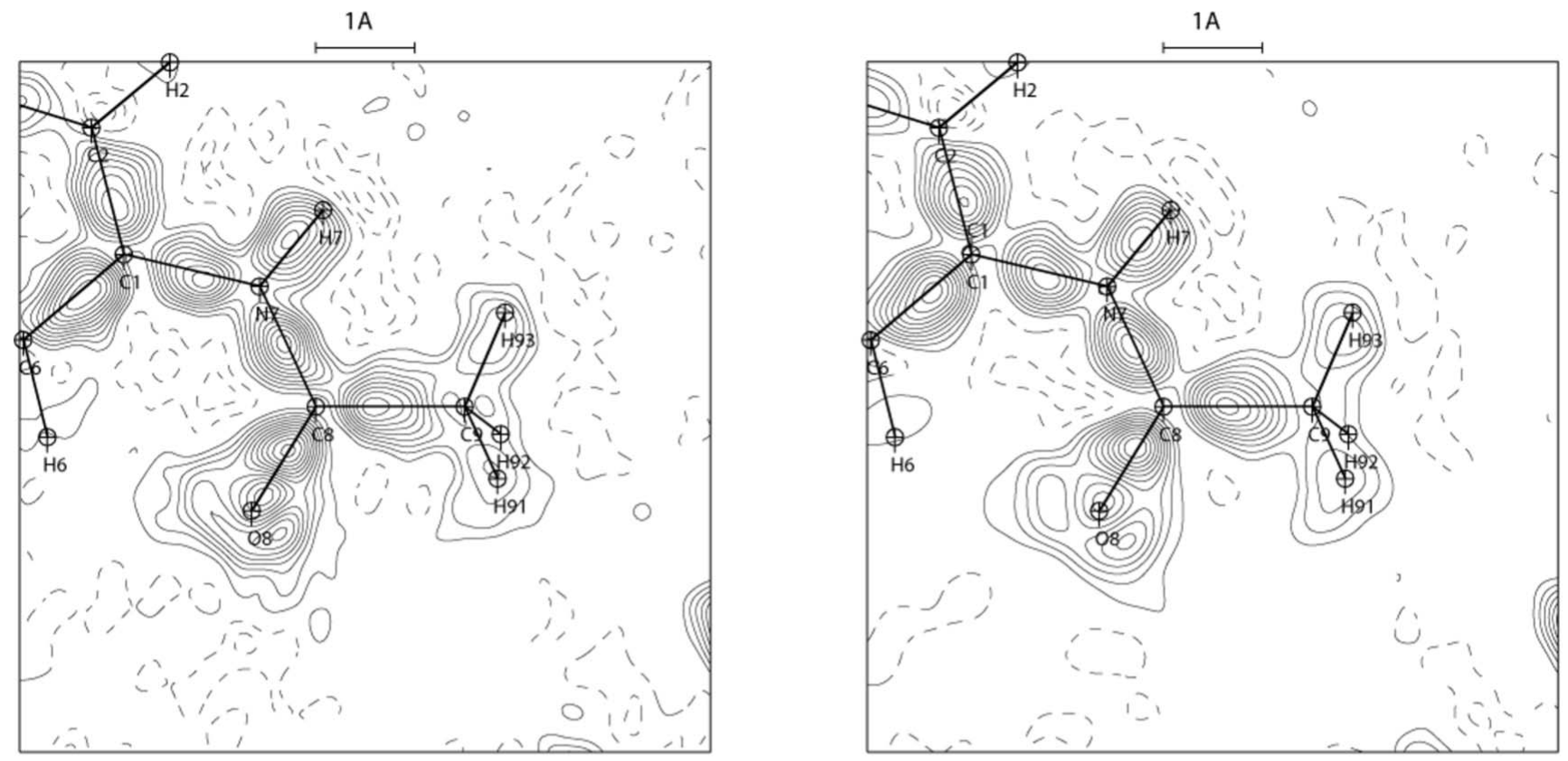

(a)

$1 \mathrm{~A}$

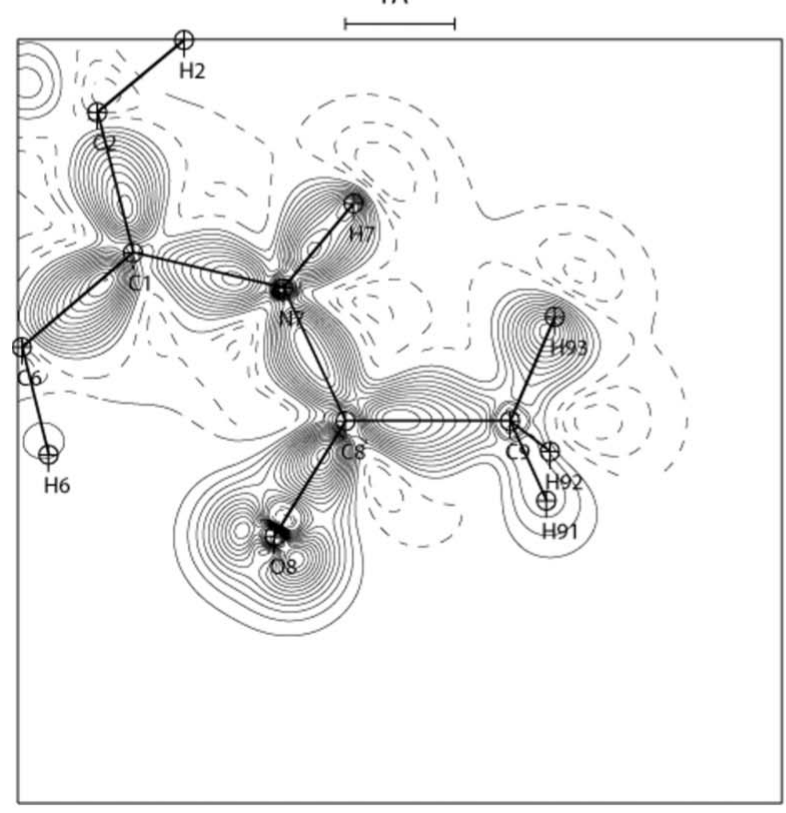

Figure 3

Deformation electron density in the $\mathrm{C} 8-\mathrm{O} 8$ region of the paracetamol molecule: $(a)$ experimental maps; $(b)$ static maps. The left and right columns correspond to refinement against the full dataset and cut-off data at $\sin \theta / \lambda=1.02 \AA^{-1}$. Contour intervals are 0.05 e $\AA^{-3}$; solid lines represent positive contours, dashed lines are negative contours and the zero contour is omitted.

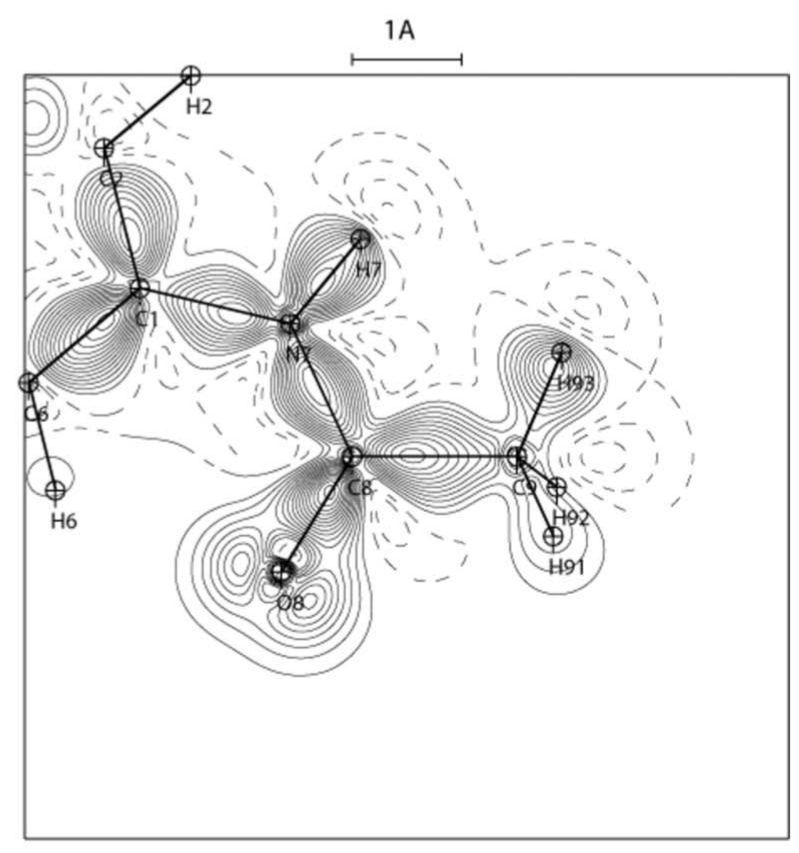

(b) 
in the refined electron density is revealed in Fig. 2 (weak residues). On the other hand, examination of the refined density parameters reveals no change except for those of the O8 atom. This is an expected result because of the abovementioned correlation of anisotropic displacement parameters and electron-density populations; atoms like oxygen are more sensitive to the cut-off of the data. For this reason we decided to use the full dataset even though the high-order data has no $100 \%$ completeness; the derived results are presented here. Practically no difference in (integrated) electrostatic properties such as electrostatic potential and field or for the interaction energies has been found between the refinement against the full and cut-off datasets.

\subsection{Molecular and crystal structure}

The structure of monoclinic paracetamol is displayed in Fig. 1. The molecule is not completely planar; with respect to the phenolic fragment, the torsion angles are $\mathrm{H} 4-\mathrm{O} 4-\mathrm{C} 4-\mathrm{C} 3=$ $18.79(4)^{\circ}$ for the hydroxyl group and $\mathrm{C} 8-\mathrm{N} 7-\mathrm{C} 1-\mathrm{C} 6=$ $-22.60(3)^{\circ}$ for the amide fragment. These values are very different from those found in monohydrate (Parkin et al., 2002) or in trihydrate paracetamol (McGregor et al., 2002). As shown in Fig. 4, paracetamol molecules form zigzag chains parallel to the $c$ axis and are interconnected via hydrogen bonds. The main hydrogen bonds involve the $\mathrm{O} 4, \mathrm{O} 8$ and $\mathrm{N} 7$ atoms. The $\mathrm{O} 4$ atom of the phenolic $\mathrm{OH}$ group is simultaneously a donor and acceptor. This gives rise to $R_{4}^{4}(22)$ rings (Bernstein et al., 1995) involving four paracetamol molecules. The hydrogen bonds create an arrangement of interconnected molecules in a sheet-like form. A weak intramolecular interaction also occurs between the $\mathrm{O} 8$ and $\mathrm{C} 6$ atoms $[\mathrm{H} 6 \cdots \mathrm{O} 8=$ 2.3183 (3) $\AA$ ]. The sheets of molecules stack by $\pi-\pi$ interactions approximately along the $b$ axis as can be seen at the bottom of Fig. 4. The distance between two face-to-face molecules is around $3.3 \AA$ and the N7 atoms point toward the centre of the adjacent phenolic ring (bottom right of Fig. 4), as can be expected from electrostatic considerations.

\subsection{Charge density and topological analysis}

The top of Fig. 5 depicts the electron-deformation density in the two main planes of the paracetamol molecule. These maps show the concentration of the electron density (solid lines) between the connected atoms and in the lone-pair regions of $\mathrm{O} 4$ (OH group) and $\mathrm{O} 8$ ( $\mathrm{CO}$ group) atoms. The depletion of the electron density, shown as dashed contours in Fig. 5, found near the $\mathrm{H}$ atoms reveals their polar character. All other features, like electron-density peak heights of $0.6-0.7$ e $\AA^{-3}$ in $\mathrm{C}-\mathrm{C}, \mathrm{C}-\mathrm{N}$ and $\mathrm{C}-\mathrm{H}$ bonds are very comparable to those reported for organic molecules. $\mathrm{C}-\mathrm{O}$ and $\mathrm{C}=\mathrm{O}$ bonds are also clearly differentiated: in the $\mathrm{C} 4-\mathrm{O} 4(\mathrm{H} 4)$ [1.3665 (3) $\mathrm{A}]$ single bond, the maximum of the deformation electron density is found to be equal to $0.50 \mathrm{e} \AA^{-3}$, whereas in the $\mathrm{C} 8=\mathrm{O} 8$ double bond [1.2394 (3) $\AA$ ] , the maximum reaches 0.85 e $\AA^{-3}$. The double $\mathrm{N} 7-\mathrm{H} 7 \cdots \mathrm{O} 4-\mathrm{H} 4 \cdots \mathrm{O} 8$ hydrogen bond $[\mathrm{O} 4 \cdots \mathrm{N} 7=2.9050(3)$ and $\mathrm{O} 4 \cdots \mathrm{O} 8=2.6535(4) \AA]$ is
Table 3

Topological properties of the electron density of paracetamol.

$\rho\left(\underline{r}_{\mathrm{CP}}\right)$ and $\nabla^{2} \rho\left(\underline{r}_{\mathrm{CP}}\right)$ are the electron density and the Laplacian values at the critical points (CP); $\varepsilon$ is the ellipticity of the bond.

\begin{tabular}{|c|c|c|c|c|c|}
\hline Bond $A-B$ & $\begin{array}{l}d(\mathrm{CP}-A) \\
(\AA)\end{array}$ & $\begin{array}{l}d(\mathrm{CP}-\mathrm{B}) \\
(\AA)\end{array}$ & $\begin{array}{l}\nabla^{2} \rho\left(\underline{r}_{\mathrm{CP}}\right) \\
\left(\mathrm{e} \AA^{-5}\right)\end{array}$ & $\begin{array}{l}\rho\left(\underline{r}_{\mathrm{CP}}\right) \\
\left(\mathrm{e} \AA^{-3}\right)\end{array}$ & $\varepsilon$ \\
\hline $\mathrm{C} 1-\mathrm{N} 7$ & 0.597 & 0.819 & -13.2 & 1.898 & 0.115 \\
\hline $\mathrm{C} 8-\mathrm{N} 7$ & 0.575 & 0.771 & -20.7 & 2.292 & 0.232 \\
\hline $\mathrm{C} 4-\mathrm{O} 4$ & 0.562 & 0.805 & -11.6 & 1.960 & 0.096 \\
\hline $\mathrm{C} 8-\mathrm{O} 8$ & 0.509 & 0.730 & -27.1 & 2.802 & 0.127 \\
\hline $\mathrm{N} 7-\mathrm{H} 7$ & 0.753 & 0.258 & -23.7 & 2.099 & 0.059 \\
\hline $\mathrm{O} 4-\mathrm{H} 4$ & 0.736 & 0.235 & -21.6 & 2.207 & 0.040 \\
\hline $\mathrm{C} 1-\mathrm{C} 2$ & 0.718 & 0.681 & -16.3 & 2.054 & 0.249 \\
\hline $\mathrm{C} 1-\mathrm{C} 6$ & 0.720 & 0.677 & -16.5 & 2.065 & 0.257 \\
\hline $\mathrm{C} 2-\mathrm{C} 3$ & 0.695 & 0.696 & -17.3 & 2.073 & 0.216 \\
\hline $\mathrm{C} 3-\mathrm{C} 4$ & 0.683 & 0.713 & -17.6 & 2.092 & 0.252 \\
\hline $\mathrm{C} 4-\mathrm{C} 5$ & 0.710 & 0.685 & -17.6 & 2.085 & 0.265 \\
\hline $\mathrm{C} 5-\mathrm{C} 6$ & 0.698 & 0.698 & -17.1 & 2.058 & 0.218 \\
\hline $\mathrm{C} 2-\mathrm{H} 2$ & 0.715 & 0.365 & -16.9 & 1.755 & 0.067 \\
\hline $\mathrm{C} 3-\mathrm{H} 3$ & 0.715 & 0.364 & -16.9 & 1.759 & 0.068 \\
\hline $\mathrm{C} 5-\mathrm{H} 5$ & 0.717 & 0.364 & -16.5 & 1.741 & 0.070 \\
\hline C6-H6 & 0.716 & 0.365 & -16.8 & 1.753 & 0.068 \\
\hline $\mathrm{C} 8-\mathrm{C} 9$ & 0.792 & 0.716 & -11.2 & 1.696 & 0.092 \\
\hline C9-H91 & 0.652 & 0.407 & -12.5 & 1.725 & 0.199 \\
\hline $\mathrm{C} 9-\mathrm{H} 92$ & 0.656 & 0.406 & -10.8 & 1.621 & 0.207 \\
\hline $\mathrm{C} 9-\mathrm{H} 93$ & 0.620 & 0.440 & -11.3 & 1.736 & 0.283 \\
\hline \multicolumn{6}{|c|}{ Hydrogen bonds } \\
\hline $\mathrm{O} 4 \cdots \mathrm{H} 7$ & 1.249 & 0.690 & +3.0 & 0.138 & 0.083 \\
\hline $\mathrm{O} 8 \cdot \cdots \mathrm{H} 4$ & 1.119 & 0.578 & +5.2 & 0.210 & 0.022 \\
\hline \multicolumn{6}{|c|}{ Intramolecular } \\
\hline O8 $\cdots \mathrm{H} 6$ & 1.330 & 1.027 & +1.5 & 0.111 & 0.130 \\
\hline
\end{tabular}

depicted in the bottom of Fig. 5. The polarization of the electron density of $\mathrm{H}$ atoms and oxygen lone pairs is clearly shown characterizing these two strong hydrogen bonds.

The topological characteristics of the electron density of the paracetamol molecule are reported in Table 3. For all bonds in the isolated molecule the Laplacian of the electron density is negative, emphasizing their shared-shell type, i.e. a covalent character with $(3,-1)$ bond-critical points (BCPs). The Laplacian is, however, positive (closed-shell type) in the hydrogen bonds. In addition to the values reported in Table 3 , a $(3,+1)$ ring $\mathrm{CP}$ was found in the center of the phenolic group at $1.38 \AA$ from the $\mathrm{C}$ atoms with $\nabla^{2} \rho\left(\underline{r}_{\mathrm{CP}}\right)=3.363 \mathrm{e} \AA^{-5}$ and $\rho\left(\underline{r}_{\mathrm{CP}}\right)=0.141$ e $\AA^{-3}$. The $\mathrm{C}-\mathrm{C}$ bonds of the phenolic group exhibit the same topological characteristics: Laplacian values in the narrow range of -16.3 to $-17.6 \mathrm{e} \AA^{-5}$ and an electron

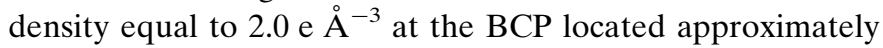
in the middle of the bonds. As can be expected for a ring fragment with a pronounced $\pi$ character, the ellipticities are high with an average value of 0.24 . The topological properties of the $\mathrm{C} 8-\mathrm{C} 9$ bond of the amide group are clearly different (Table 3). $\mathrm{C}-\mathrm{H}$ bonds of the phenolic ring have the same topological properties: on average $\nabla^{2} \rho\left(\underline{r}_{\mathrm{CP}}\right)=-16.9 \mathrm{e} \AA^{-5}$, 
$\rho\left(\underline{r}_{\mathrm{CP}}\right)=1.75 \mathrm{e} \AA^{-3}$ and $\varepsilon=0.07$. For the methyl group, the electron-density values at the bond-critical points are comparable to those of aromatic $\mathrm{C}-\mathrm{H}$ bonds, but the Laplacian is lower with values around $-11.0 \mathrm{e} \AA^{-5}$. However, the ellipticities for $\mathrm{C}-\mathrm{H}$ of the methyl group are in the range $0.2-0.3$, significantly higher than those of aromatic $\mathrm{C}-\mathrm{H}$ bonds. For comparison, more polar bonds such as $\mathrm{N} 7-\mathrm{H} 7$ and $\mathrm{O} 4-\mathrm{H} 4$ have higher Laplacian values $\left(-22.5 \mathrm{e} \AA^{-5}\right.$ on average) and concentrations of electron density at the $\mathrm{BCP}$ $\left(2.1 \mathrm{e}^{-3}\right)$. Finally, the difference in strength of the $\mathrm{C}-\mathrm{N}$ and $\mathrm{C}-\mathrm{O}$ bonds is clearly shown in Table 3 through their topological features. The shortest $\mathrm{C} 8-\mathrm{N} 7$ and $\mathrm{C} 8=\mathrm{O} 8$ bonds exhibit the highest magnitudes of Laplacian and electron density at the critical-point sites. All the values given in Table 3 are in good agreement with those reported in the

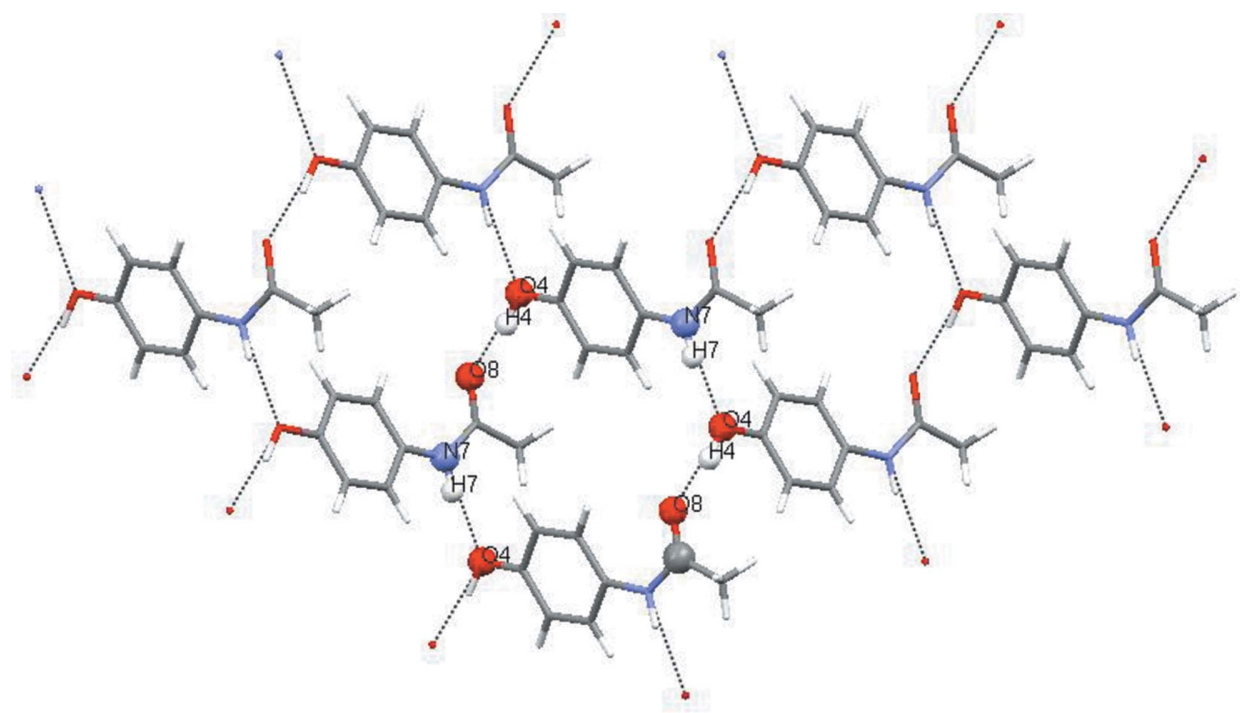

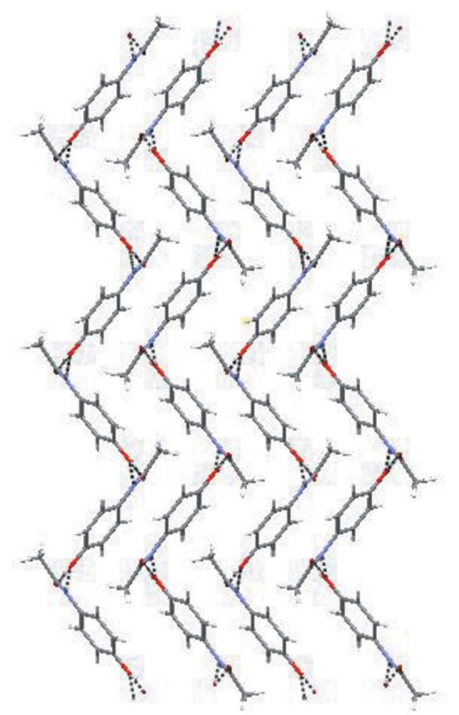

(b) (a)

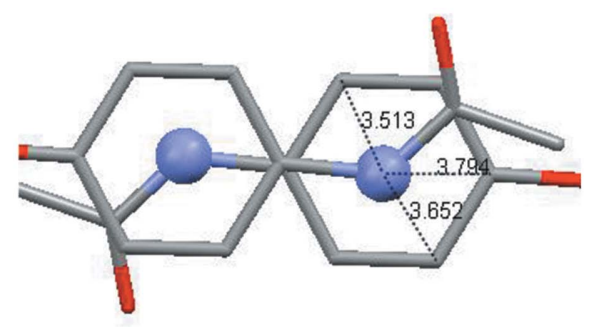

(c)
Figure 4

Hydrogen-bond network in the monoclinic paracetamol lattice and molecular stacking. (a) View along the $b$ axis, with the $c$ axis lying horizontally; $(b)$ view along the $a$ axis, with $b$ horizontal. (c) Stacking of the paracetamol molecules; the numbers indicate the distance between the N7 (in ball) and the Catoms of the phenolic fragment of the adjacent molecule. comparative topological study of peptides and amino acids (Benabicha et al., 2000).

\subsection{Electrostatic potential and field}

The electrostatic potential generated by an isolated molecule of paracetamol is displayed in Fig. 6. On one side of the molecule, from $\mathrm{H} 4$ ( $\mathrm{OH}$ group) to the methyl group, a large region of positive electrostatic potential (electrophilic region) is displayed. The negative electrostatic potential (nucleophilic part) is generated not only by the most negatively charged $\mathrm{O}$ atoms, $\mathrm{O} 4$ and $\mathrm{O} 8$, but also by the delocalized electrons of the phenolic ring. The minimum of the electrostatic potential is found in the vicinity of the $\mathrm{O} 8$ atom and reaches -0.233 e $\AA^{-1}$. The topology of the electrostatic potential was carried out using the electric field. Fig. 7 depicts the gradient lines around the paracetamol molecule as obtained by our computer program FIELD (Ghermani et al., 1992c). As for the electron density, the zero-flux surfaces of the electric field lines define atomic basins with different shapes in relation to their chemical environment and hybridization: $s p^{3} \mathrm{C}$ and $\mathrm{N}$ basins have a prismatic form, whereas $\mathrm{O}$ atoms have a drop-like shape. Peripheral $\mathrm{H}$ atoms, however, exhibit open volumes. From Gauss's law, these atomic basins are obviously neutral since the electric field is tangent to the atomic surface or vanishes at the critical points. Therefore, the electron density inside the atomic basin neutralizes the positive charge of the nucleus. For comparison, the Bader atomic basins (based on the electron density) are also projected for some atoms in Fig. 7. Negatively charged atoms such as $\mathrm{O}$ and $\mathrm{N}$ exhibit larger Bader atomic basins compared with those obtained from the topology of the electrostatic potential. Conversely, positively charged atoms (like C8) have smaller Bader's atomic basins.

In Fig. 7 different kinds of critical points are shown: $(3,-1)$ saddle BCPs between covalently linked atoms or in the hydrogen bonds, $(3,+3)$ local minimum critical points 


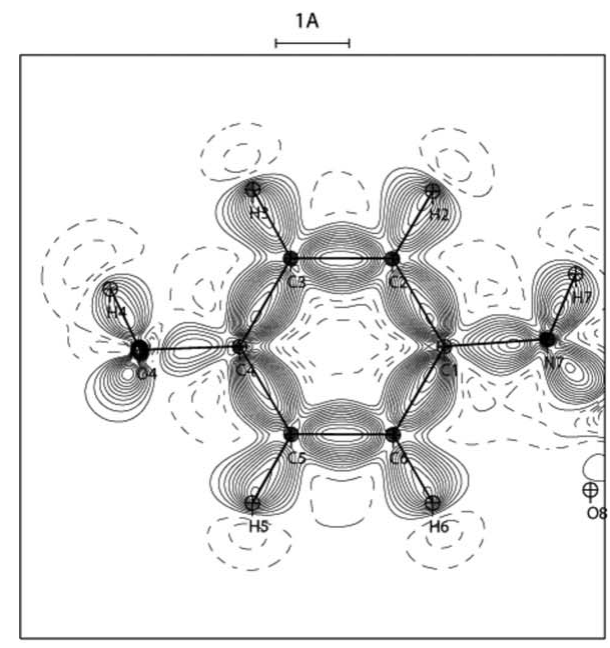

(a)

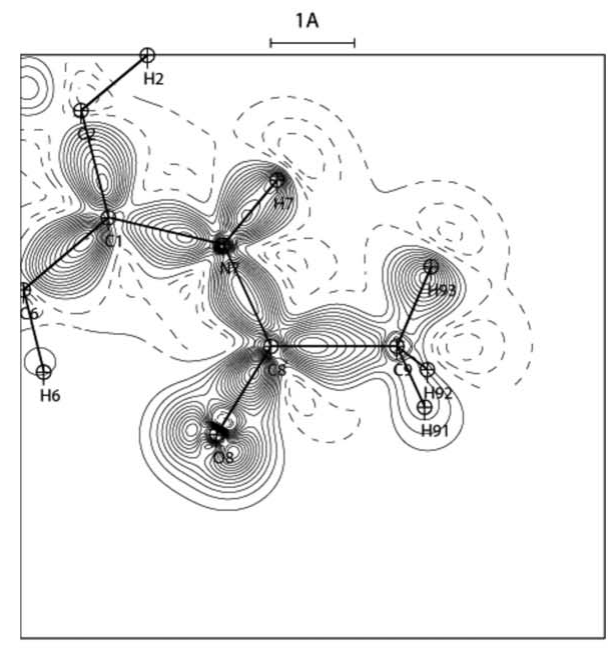

(b)

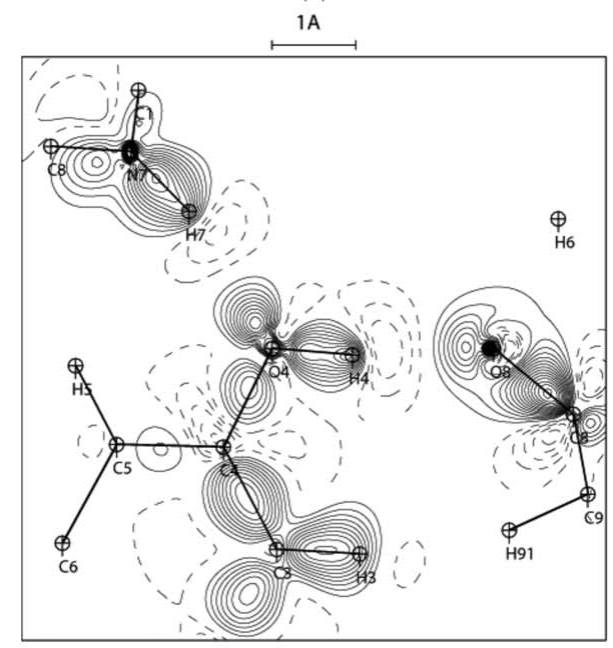

(c)

\section{Figure 5}

Static electron deformation-density maps. Top: in the two main planes of the isolated paracetamol molecule: phenolic ring $(a)$ and amide fragment (b). Bottom: in the plane of the double hydrogen bond $\mathrm{N} 7-\mathrm{H} 7 \cdots \mathrm{O} 4-$ $\mathrm{H} 4 \cdots \mathrm{O} 8(c)$. Contour intervals are $0.05 \mathrm{e}^{-3}$; solid lines represent positive contours, dashed lines are negative contours and the zero contour is omitted. found near $\mathrm{O}$ atoms and $(3,+1)$ ring-critical point found in the center of the phenolic group. It was previously shown that the distances from the BCP and the connecting atoms can define the atomic covalent radii (Bouhmaida et al., 2002). It is worthy to note that other $(3,+1)$ ring-critical points, not reported in Fig. 7, were found close to $\mathrm{H} 4$ and $\mathrm{H} 3$, and in the regions of atoms $\mathrm{H} 2, \mathrm{H} 7, \mathrm{H} 7$ and $\mathrm{H} 93$. Topological features of the electrostatic potential are given in Table 4. Values of the electrostatic potential $\Phi\left(\underline{r}_{C P}\right)$ and electron density $\rho\left(\underline{r}_{\mathrm{CP}}\right)$ at different CPs are reported. Especially for the $(3,-1)$ saddle BCPs, the competition between the contribution of the positive charge of the nucleus and the surrounding electron density is highlighted. As expected, the values of the electron density at these potential BCPs are higher than those found at the electron density BCPs. These accumulations are the consequence of the stabilization of the electrostatic force between the two atoms during the bond formation (Bader, 1990).

\subsection{Atomic charges and forces}

Table 5 reports the AIM atomic charges calculated by different methods. The charges calculated by the electric flux [see (3)] are consistent with those obtained by the conventional volume integration methods. The differences do not exceed $0.11 \mathrm{e}$ between the charges from BADERWIN (Sanville et al., 2007) and those from the flux of the electric field. However, discrepancies are larger between the charges obtained from NEWPROP (Souhassou, 1999; Souhassou \& Blessing, 1999) and those of the two other methods, and even reach 0.35 e for the $\mathrm{C} 9$ atom. In all the calculations the atomic charges are in agreement with the chemical environment in the paracetamol molecule: the most negative charges are carried by $\mathrm{O} 4, \mathrm{O} 8$ and $\mathrm{N} 7$, this latter being slightly more charged than both the two $\mathrm{O}$ atoms. As can also be expected, the most positive charge $(+1.0 \mathrm{e})$ is obtained for the $\mathrm{C} 8$ atom of the $\mathrm{C}=\mathrm{O}$ group. Finally, $\mathrm{H} 4$ bonded to $\mathrm{O} 4$ and $\mathrm{H} 7$ bonded to $\mathrm{N} 7$ exhibit the highest positive charges among the $\mathrm{H}$ atoms of paracetamol. An obvious consistency is observed between the atomic charge distribution and the features of the molecular electrostatic potential (Fig. 6): the negative region envelopes the external negatively charged $\mathrm{O} 4$ and $\mathrm{O} 8$ atoms, while the $\mathrm{N} 7$ atom screened off by the surrounding atoms exhibits in its vicinity a positive electrostatic potential. This agrees with the expected nucleophilic attack on this N7 after the deacetylation of the paracetamol molecule in the organism yielding a reactive metabolite to form the AM404 inhibitor (Högestätt et al., 2005) responsible of the analgesic action of this drug.

As explained in $\S 3$ we have calculated the experimental electrostatic forces acting on each atomic basin of the paracetamol using the flux of the Maxwell stress tensor [see (9)]. The values are reported in the last column of Table 5. The forces are given in $\mathrm{e}^{2} \AA^{-2}$ units which correspond to $23.1 \mathrm{nN}$ (SI units). The individual atomic forces do not vanish, thus showing the cohesion of the molecule. Conversely, the total 
Table 4

Topological properties of the electrostatic potential of paracetamol.

$\rho\left(\underline{r}_{\mathrm{CP}}\right)$ and $\Phi\left(\underline{r}_{\mathrm{CP}}\right)$ are the electron density and the electrostatic potential values at the critical points $(\mathrm{CP})$.

\begin{tabular}{|c|c|c|c|c|}
\hline Bond $A-B$ & $\begin{array}{l}d(\mathrm{CP}-A) \\
(\AA)\end{array}$ & $\begin{array}{l}d(\mathrm{CP}-\mathrm{B}) \\
(\AA)\end{array}$ & $\begin{array}{l}\rho\left(\underline{r}_{C P}\right) \\
\left(\mathrm{e} \AA^{-3}\right)\end{array}$ & $\begin{array}{l}\Phi\left({ }_{r} \mathrm{cP}\right) \\
\left(\mathrm{e} \AA^{-1}\right) \\
\end{array}$ \\
\hline $\mathrm{C} 1-\mathrm{N} 7$ & 0.719 & 0.697 & 2.085 & 1.446 \\
\hline $\mathrm{C} 8-\mathrm{N} 7$ & 0.682 & 0.665 & 2.467 & 1.768 \\
\hline $\mathrm{C} 4-\mathrm{O} 4$ & 0.699 & 0.668 & 2.258 & 1.603 \\
\hline $\mathrm{C} 8-\mathrm{O} 8$ & 0.627 & 0.613 & 3.100 & 2.136 \\
\hline $\mathrm{N} 7-\mathrm{H} 7$ & 0.637 & 0.374 & 2.903 & 1.861 \\
\hline $\mathrm{O} 4-\mathrm{H} 4$ & 0.614 & 0.356 & 2.590 & 1.909 \\
\hline $\mathrm{C} 1-\mathrm{C} 2$ & 0.699 & 0.700 & 2.130 & 1.492 \\
\hline $\mathrm{C} 1-\mathrm{C} 6$ & 0.699 & 0.698 & 2.140 & 1.447 \\
\hline $\mathrm{C} 2-\mathrm{C} 3$ & 0.696 & 0.695 & 2.139 & 1.532 \\
\hline $\mathrm{C} 3-\mathrm{C} 4$ & 0.698 & 0.698 & 2.163 & 1.483 \\
\hline $\mathrm{C} 4-\mathrm{C} 5$ & 0.699 & 0.697 & 2.153 & 1.472 \\
\hline C5-C6 & 0.698 & 0.698 & 2.143 & 1.475 \\
\hline $\mathrm{C} 2-\mathrm{H} 2$ & 0.684 & 0.396 & 1.845 & 1.583 \\
\hline $\mathrm{C} 3-\mathrm{H} 3$ & 0.683 & 0.396 & 1.832 & 1.567 \\
\hline $\mathrm{C} 5-\mathrm{H} 5$ & 0.685 & 0.396 & 1.797 & 1.500 \\
\hline $\mathrm{C} 6-\mathrm{H} 6$ & 0.685 & 0.395 & 1.781 & 1.474 \\
\hline $\mathrm{C} 8-\mathrm{C} 9$ & 0.758 & 0.751 & 1.775 & 1.252 \\
\hline C9-H91 & 0.673 & 0.386 & 1.747 & 1.758 \\
\hline $\mathrm{C} 9-\mathrm{H} 92$ & 0.675 & 0.386 & 1.728 & 1.848 \\
\hline $\mathrm{C} 9-\mathrm{H} 93$ & 0.676 & 0.385 & 1.695 & 1.788 \\
\hline \multicolumn{5}{|l|}{ Hydrogen bonds } \\
\hline $\mathrm{O} 4 \cdots \mathrm{H} 7$ & 0.988 & 0.960 & 0.300 & 0.117 \\
\hline $\mathrm{O} 8 \cdots \mathrm{H} 4$ & 0.920 & 0.777 & 0.448 & 0.322 \\
\hline \multicolumn{5}{|c|}{ Local minima $(3,+3) \mathrm{CP}$} \\
\hline $\mathrm{O} 4$ & 1.206 & & 0.099 & -0.210 \\
\hline 08 & 1.205 & & 0.090 & -0.233 \\
\hline $\mathrm{C} 1$ & 1.821 & & 0.025 & -0.146 \\
\hline C6 & 1.692 & & 0.020 & -0.098 \\
\hline \multicolumn{5}{|l|}{ Ring $(3,+1) \mathrm{CP}$} \\
\hline Phenolic center & & & 0.145 & 0.163 \\
\hline
\end{tabular}
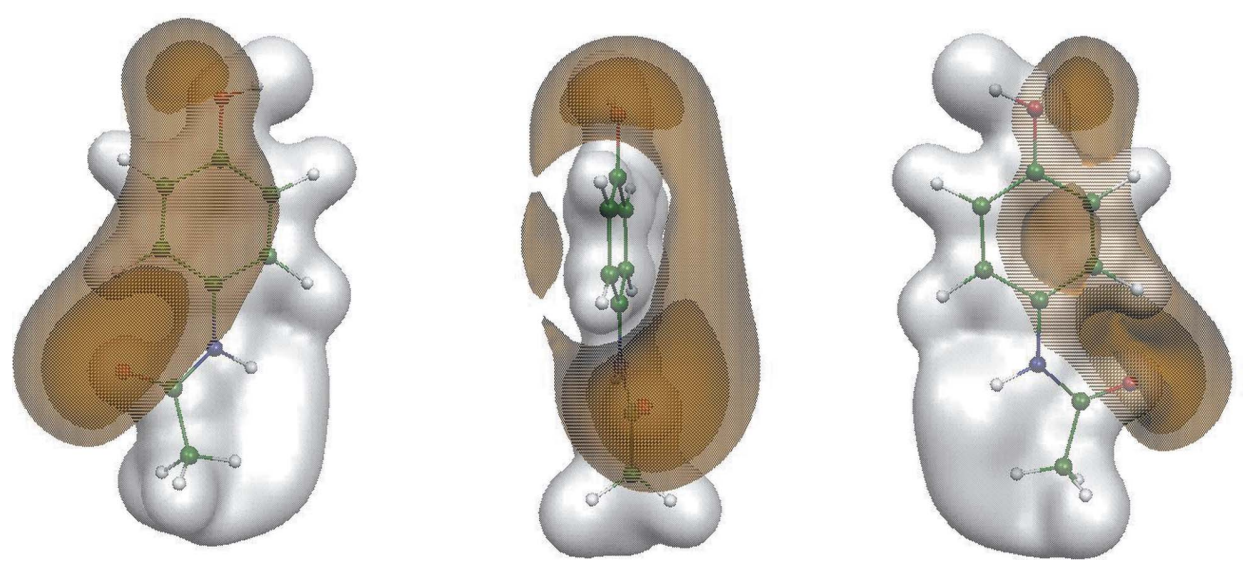

Figure 6

Electrostatic potential of the paracetamol for three orientations of the molecule. The pale grey isosurface corresponds to +0.15 e $\AA^{-1}$. Two isovalues of the negative electrostatic potential are presented in brown, -0.15 (inner surface) and $-0.10 \mathrm{e}^{-1}$ (outer surface). This figure is in colour in the electronic version of this paper.
Table 5

AIM topological charges (e unit) and moduli of the total electrostatic forces $\left(\mathrm{e}^{2} \AA^{-2}\right.$ unit) in paracetamol.

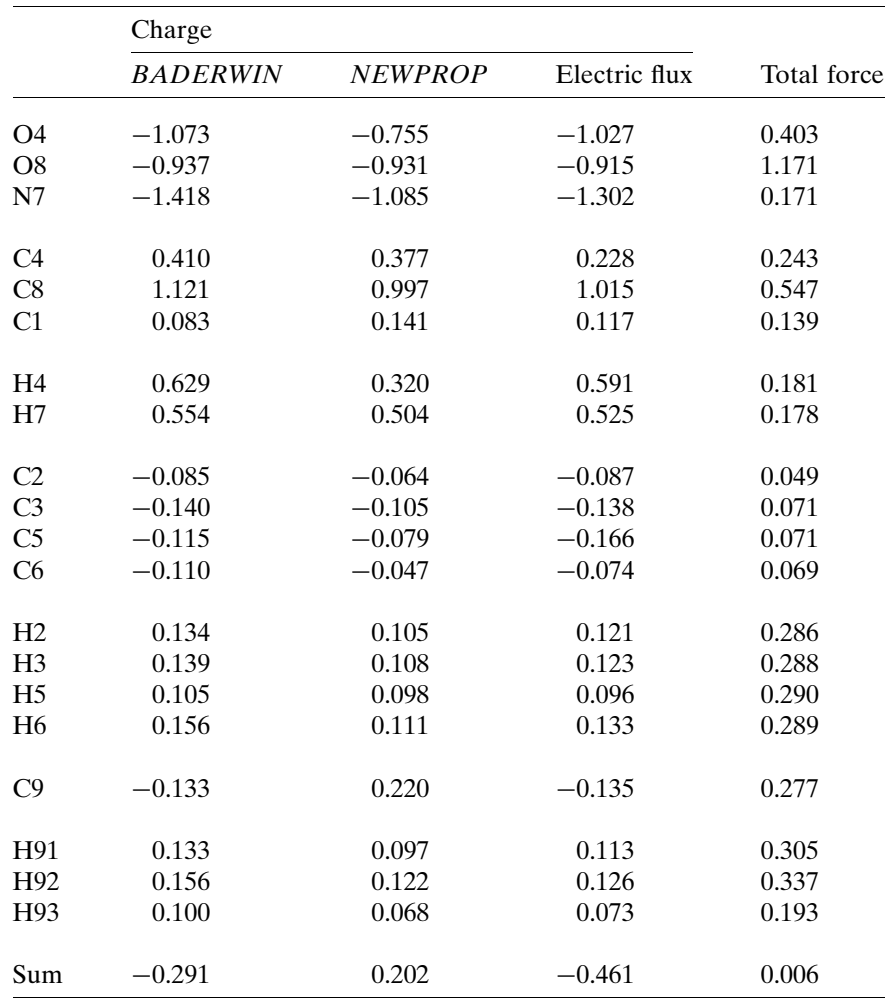

electrostatic force exerted on the external molecular surface is zero (last value in Table 5). As we have reported earlier (Bouhmaida \& Ghermani, 2008), the atomic electrostatic force reflects the anisotropy of the electron density in different bonding directions and therefore is related to the hybridization state and also to the local symmetry of the atomic site. Recall that the Maxwell stress tensor [see (4)] has a dimension of pressure and therefore its offdiagonal elements $E_{i} E_{j}$ are both sensitive to the sign of the electrostatic potential and to its gradient magnitude. In Table 5 the moduli of the electrostatic forces vary in a wide range from 0.05 to $1.2 \mathrm{e}^{2} \AA^{-2}$. However, some trends can be observed for the different groups of atoms in the molecule: $\mathrm{C} 4-\mathrm{O} 4$ having atomic force moduli of 0.243 and $0.403 \mathrm{e}^{2} \AA^{-2}, \quad \mathrm{C} 8=\mathrm{O} 8 \quad$ with atomic force moduli of 0.547 and $1.171 \mathrm{e}^{2} \AA^{-2}$. It is worth noting that these bonds are in the regions where the negative potential gradient is increasing. The positive region of $\mathrm{C} 1-\mathrm{N} 7$ exhibits, however, small force values of 0.14 and $0.17 \mathrm{e}^{2} \AA^{-2}$. 
Table 6

List of dimers in the crystal packing.

The two closest interacting atoms for each dimer, the distance and the symmetry relating the two molecules are indicated. The dimers are ranked according to the electrostatic interaction energy. The involutive symmetry operators are marked (inv).

\begin{tabular}{lllllc}
\hline Dimer no. & Atom 1 & Atom 2 & Distance $(\AA)$ & Symmetry & $E_{\text {def }}\left(\mathrm{kJ} \mathrm{mol}^{-1}\right)$ \\
\hline 1 & O4 & H7 & 1.9275 & $x-\frac{1}{2},-y+\frac{1}{2}, z-\frac{1}{2}$ & -63.76 \\
2 & O8 & H4 & 1.6966 & $x-\frac{1}{2},-y+\frac{1}{2}, z+\frac{1}{2}$ & -46.68 \\
3 & H92 & O8 & 2.7062 & $-x+\frac{3}{2}, y-\frac{1}{2},-z+\frac{3}{2}$ & -41.28 \\
4 & H92 & H4 & 2.6565 & $-x+2,-y,-z+1$ (inv) & -23.82 \\
5 & H93 & H2 & 2.5015 & $-x+\frac{5}{2}, y-\frac{1}{2},-z+\frac{3}{2}$ & -1.34 \\
6 & H6 & H6 & 2.2263 & $-x+1,-y,-z+1$ (inv) & -0.04 \\
7 & H5 & H4 & 2.7269 & $-x+\frac{3}{2}, y-\frac{1}{2},-z+\frac{1}{2}$ & 7.16 \\
\hline
\end{tabular}

intermolecular interactions. In the twin dimers the reference and neighbouring molecules are related by inverse symmetric operators. For two of the dimers (\#6 and \#7), the symmetry operator is involutive. Therefore, there are seven independent dimers in the crystal. The electrostatic energy due to the deformation part of the electron density was computed for the interacting dimers (Table 6). The first two dimers with the strongest interaction correspond to the two hydrogen bonds $\mathrm{O} 4 \cdots \mathrm{H} 7-\mathrm{N} 7$ and $\mathrm{O} 8 \cdot \mathrm{H} 4-\mathrm{O} 4$. The interaction of the deformation densities can be seen in Fig. 5(c). The third dimer consists of a weak O8...H92C9 hydrogen bond. The other dimers occurring

The $\mathrm{C} 2, \mathrm{C} 3, \mathrm{C} 5$ and $\mathrm{C} 6$ phenolic $\mathrm{C}$ atoms have an average force modulus of $0.06 \mathrm{e}^{2} \AA^{-2}$ reflecting a nearly isotropic electron density. $\mathrm{C}$ atoms linked to $\mathrm{H}$ atoms have force moduli varying from 0.29 to $0.33 \mathrm{e}^{2} \AA^{-2}$, except for the $\mathrm{H} 93$ atom $\left(0.19 \mathrm{e}^{2} \AA^{-2}\right)$. A lower value $\left(0.18 \mathrm{e}^{2} \AA^{-2}\right)$ is observed for $\mathrm{H} 4$ and $\mathrm{H} 7$ bonded to $\mathrm{O} 4$ and $\mathrm{N} 7$ atoms and involved in strong hydrogen bonding.

\subsection{Electrostatic energy between dimers}

Each paracetamol molecule is involved in 12 intermolecular contacts in the crystal lattice (Table 6). Five of the dimers of molecules actually have a twin dimer which displays the same in the crystal correspond to weak van der Waals contacts, with the shortest distances involving $\mathrm{H} \cdot \cdots \mathrm{H}$ interactions.

\section{Conclusions}

The current study provides an experimental analysis of the features of the electron density and electrostatic properties of monoclinic paracetamol. Characterization of the chemical bonds is established from the topological analysis of both electron density and electrostatic potential. Atomic basin surfaces are triangulated using a rigorous Delaunay procedure which allows the flux of the electric field and the Maxwell
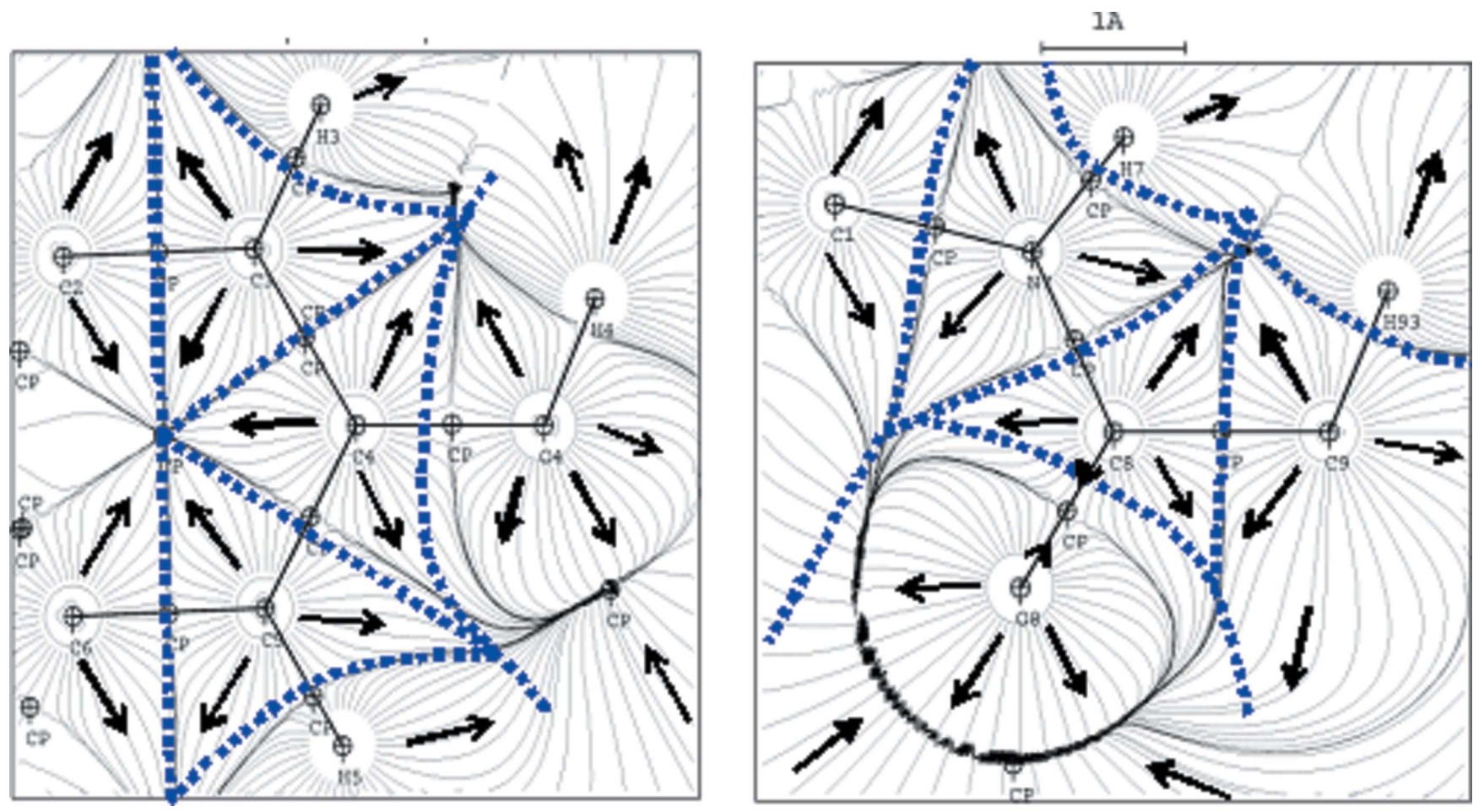

Figure 7

Electric field lines of the paracetamol molecule. The dotted bold lines are the boundaries of the Bader's atomic basins. The arrows indicate the directions of the electric field. 'CP' designates the critical points of the electrostatic potential. 
stress tensor to be estimated. This yields numerical estimates for the atomic charge and electrostatic force. Computed values of the electrostatic energy of paracetamol dimers in the crystal lattice are also given.

We are very grateful to Paul Louis Georges and Patrick Laug of the INRIA, Rocquencourt, and to Pascal Frey, Université Pierre et Marie Curie, for providing us with their triangulation and remeshing software. The financial support of the Université Cadi Ayyad, Université Paris-Sud 11, Ecole Centrale Paris, Université Henri Poincaré, Nancy 1, CNRS, and Agence Nationale de la Recherche (ANR) is also gratefully acknowledged.

\section{References}

Bader, R. F. W. (1990). Atoms in Molecules: A Quantum Theory. Oxford: Clarendon Press.

Bader, R. F. W. (1998). J. Phys. Chem. A, 102, 7314-7323.

Bader, R. F. W., Hernández-Trujillo, J. \& Cortés-Guzmán, F. (2007). J. Comput. Chem. 28, 4-14.

Benabicha, F., Pichon-Pesme, V., Jelsch, C., Lecomte, C. \& Khmou, A. (2000). Acta Cryst. B56, 155-165.

Bernstein, J., Davis, R. E., Shimoni, L. \& Chang, N.-L. (1995). Angew. Chem. Int. Ed. Engl. 34, 1555-1573.

Blessing, R. H. (1995). Acta Cryst. A51, 33-38.

Bouhmaida, N., Dutheil, M., Ghermani, N. E. \& Becker, P. (2002). J. Chem. Phys. 116, 6196-6204.

Bouhmaida, N. \& Ghermani, N. E. (2008). Phys. Chem. Chem. Phys. 10, 3934-3941.

Bouhmaida, N., Ghermani, N.-E., Lecomte, C. \& Thalal, A. (1997). Acta Cryst. A53, 556-563.

Bruker (1998a). SMART, Version 5.054. Bruker AXS Inc., Madison, Wisconsin, USA.

Bruker (1998b). SAINT, Version 6.36A. Bruker AXS Inc., Madison, Wisconsin, USA.

Bruker (1998c). SADABS, Version 2.05. Bruker AXS Inc., Madison, Wisconsin, USA.

Burnett, M. N. \& Johnson, C. K. (1996). ORTEPIII, Report ORNL6895. Oak Ridge National Laboratory, Oak Ridge, Tennessee, USA.

Clementi, E. \& Roetti, C. (1974). At. Data Nucl. Data Tables, 14,177478.

Coppens, P., Guru Row, T. N., Leung, P., Stevens, E. D., Becker, P. J. \& Yang, Y. W. (1979). Acta Cryst. A35, 63-72.

Courcot, B., Tran, D. N., Fraisse, B., Bonhomme, F., Marsura, A. \& Ghermani, N. E. (2007). Chem. Eur. J. 13, 3414-3423.
Cruickshank, D. W. J. (1949). Acta Cryst. 2, 65-82.

Di Martino, P., Conflant, P., Drache, M., Huvenne, J.-P. \& GuyotHermann, A.-M. J. (1997). Therm. Anal. 48, 447-458.

Farrugia, L. J. (1999). J. Appl. Cryst. 32, 837-838.

George, P. L. (1996). GHS3D: Tetrahedral Mesh Generator. INRIA Simulog. Gamma Project, Rocquencourt, France.

Ghermani, N. E., Bouhmaida, N. \& Lecomte, C. (1992a). ELECTROS Internal Report UMR CNRS 7036, Université Henri Poincaré, Nancy 1, France.

Ghermani, N. E., Bouhmaida, N. \& Lecomte, C. (1992b). STATDENS. Internal Report UMR CNRS 8612, Université Paris-Sud 11, France.

Ghermani, N. E., Bouhmaida, N. \& Lecomte, C. (1992c). FIELD. Université Cadi Ayyad, Morocco.

Guillot, B., Viry, L., Guillot, R., Lecomte, C. \& Jelsch, C. (2001). J. Appl. Cryst. 34, 214-223.

Haisa, M., Kashino, S., Kawai, R. \& Maeda, H. (1976). Acta Cryst. B32, 1283-1285.

Hansen, N. K. \& Coppens, P. (1978). Acta Cryst. A34, 909921.

Henkelman, G., Arnaldsson, A. \& Jónsson, H. (2006). Comput. Mater. Sci. 36, 354-360.

Hernández-Trujillo, J., Cortés-Guzmán, F., Fang, D.-C. \& Bader, R. F. W. (2007). Faraday Discuss. 135, 79-95.

Högestätt, E. D., Jönsson, B. A. G., Ermund, A., Andersson, D. A., Björk, H., Alexander, J. P., Cravatt, B. F., Basbaum, A. I. \& Zygmunt, P. M. (2005). J. Biol. Chem. 36, 31405-31412.

Jain, S. (1999). Pharm. Sci. Technol. Today, 2, 20-31.

Jelsch, C., Guillot, B., Lagoutte, A. \& Lecomte, C. (2005). J. Appl. Cryst. 38, 38-54.

McGregor, P. A., Allan, D. R., Parsons, S. \& Pulham, C. R. (2002). J. Pharm. Sci. 91, 1308-1311.

Nichols, G. \& Frampton, C. S. (1998). J. Pharm. Sci. 87, 684-693.

Novaković, S. B., Bogdanović, G. A., Fraisse, B., Ghermani, N. E., Bouhmaida, N. \& Spasojević-de Biré, A. (2007). J. Phys. Chem. A, 111, 13492-13505.

Parkin, A., Parsons, S. \& Pulham, C. R. (2002). Acta Cryst. E58, o1345-o1347.

Popelier, P. L. A. (2001). Theor. Chem. Acc. 105, 393-399.

Rees, B. (1976). Acta Cryst. A32, 483-488.

Sanville, E., Kenny, S. D., Smith, R. \& Henkelman, G. (2007). J. Comput. Chem. 28, 899-908.

Sheldrick, G. M. (2008). Acta Cryst. A64, 112-122.

Silva López, C., Nieto Faza, O., Cossío, F. P., York, D. M. \& de Lera, A. R. (2005). Chem. Eur. J. 11, 1734-1738.

Souhassou, M. (1999). NEWPROP. LCM3B, Université Henri Poincaré Nancy 1, France.

Souhassou, M. \& Blessing, R. H. (1999). J. Appl. Cryst. 32, 210-217. Wilson, C. C. (2000). Z. Kristallogr. 215, 693-701. 